\title{
Krüppel-like factor 4 negatively regulates $\beta$-catenin expression and inhibits the proliferation, invasion and metastasis of gastric cancer
}

\author{
NENG ZHANG, JUN ZHANG, LEIYUAN SHUAI, LANG ZHA, MIAO HE, ZHEN HUANG and ZIWEI WANG \\ Department of General Surgery, The First Affiliated Hospital of Chongqing Medical University, \\ Chongqing 400016, P.R. China
}

Received December 9, 2011; Accepted February 2, 2012

DOI: $10.3892 /$ ijo.2012.1395

\begin{abstract}
Krüppel-like factor 4 (KLF4) is a zinc-finger protein that plays an important role in the progression of gastric carcinoma. The abnormal activation of $\beta$-catenin frequently occurs in gastric cancer and has been associated with the promotion of tumor growth, invasion and metastasis. However, the potential interaction between KLF4 and $\beta$-catenin during gastric cancer development is unknown. In this study, a lentiviral KLF4 expression vector was constructed and utilized to transfect the human gastric cancer cell lines, SGC-7901, BGC-823, MKN-28 and MKN-45. KLF4 and $\beta$-catenin expression levels were measured by quantitative real-time RT-PCR and western blot analysis. Cell proliferation, colony formation and invasive potential were determined in the KLF4-transfected gastric cancer cells. The expression of E-cadherin and matrix metallopeptidase 2 (MMP2) was determined by western blot analysis. The overexpression of KLF4 significantly inhibited the expression of $\beta$-catenin in the MKN-45 gastric cancer cells. The restored expression of KLF4 suppressed proliferation, colony formation and inhibited the invasion and metastatic properties of MKN-45 gastric cancer cells. Furthermore, the forced expression of KLF4 in gastric tumor cell lines restored E-cadherin expression and inhibited MMP2 expression. Consistent with the in vitro findings, the enforced expression of the KLF4 gene in MKN-45 gastric carcinoma cells by lentiviral vector-mediated gene transfer effectively suppressed tumor growth in vivo. Our results show that KLF4 inhibits $\beta$-catenin expression and regulates the $\beta$-catenin-mediated biological behaviors of gastric cancer cells. The modulation of KLF4 expression may represent a novel therapeutic approach for $\beta$-catenin-driven malignancies.
\end{abstract}

Correspondence to: Professor Ziwei Wang, Department of General Surgery, The First Affiliated Hospital of Chongqing Medical University, Chongqing 400016, P.R. China

E-mail: wangziwei571@hotmail.com

Key words: Krüppel-like factor 4, $\beta$-catenin, gastric cancer, invasion, proliferation

\section{Introduction}

Although the incidence and mortality of gastric cancer is declining, it remains the fourth most common epithelial malignancy and the second leading cause of cancer-related mortality following lung carcinoma throughout the world $(1,2)$. Gastric cancer is characterized by high regional lymph node invasion and distant metastasis, which are important factors that lead to recurrence and negatively affect the prognosis of gastric carcinomas (3-5). Therefore, there is a critical need to understand the molecular mechanisms that regulate regional lymph node invasion and distant metastasis of gastric cancer in order to develop novel treatment options for this deadly disease.

Invasion and metastasis are often associated with a number of molecular abnormalities, including the inactivation of the tumor suppressor, Krüppel-like factor 4 (KLF4), and activation of the oncogene, $\beta$-catenin $(6,7)$. KLF4 has been identified as a zinc-finger transcription factor that is highly expressed in the epithelial cells of several organs (8-10), especially in the epithelium of the gastrointestinal tract (11-13). Previous studies have confirmed that KLF4 is a negative regulator of the cell cycle, and its expression pattern correlates with terminal differentiation via the suppression of proliferative genes and the up-regulation of inhibitors of proliferation (14). KLF4 also plays a key role in the differentiation of various organs during embryonic development (15). KLF4-null mice die from dehydration immediately after birth due to severe defects in late-stage differentiation of epidermal cells (8). In addition, KLF4 functions to maintain self-renewal through the regulation of pluripotency gene expression (15). Several studies have discovered KLF4 expression is decreased in benign and malignant tumors in the digestive tract, including early intestinal adenomas, colonic adenomas and adenocarcinomas, as well as esophageal and gastric cancer (16-19). These findings suggest that KLF4 plays an important role as a suppressor of tumor development and that the lack of KLF4 expression may play a role in tumor progression.

As a multifunctional protein, $\beta$-catenin is a transcriptional co-activator of $\mathrm{T}$ cell factor (TCF)/lymphoid enhancer factor (LEF) transcription factors and acts as a crucial factor in the cadherin-catenin complex that mediates intercellular adhesion (20). $\beta$-catenin also plays an important role in many processes, such as cell growth, differentiation, embryogenesis, 
tumorigenesis, and the growth and maintenance of stem cells (21-23). In normal cells, the cytoplasmic levels of $\beta$-catenin are tightly regulated by interactions with adenomatous polyposis coli (APC), glycogen synthase kinase $3 \beta$ (GSK-3 $\beta$ ) and axin proteins. The APC-axin-GSK-3 $\beta$ complex normally promotes the degradation of $\beta$-catenin via the phosphorylation of serine and threonine residues in the $\mathrm{N}$-terminal region of $\beta$-catenin (21). When activated by Wnt-signaling, the degradation of $\beta$-catenin is inhibited and the cytoplasmic levels of $\beta$-catenin stabilize, resulting in the formation of the $\beta$-catenin-LEF/TCF complex in the nucleus. In the nucleus, $\beta$-catenin acts as a transcription factor and activates target genes, such as cyclinD1 and c-Myc (24). $\beta$-catenin has been shown to function as an oncogene in a variety of tumor types $(25,26)$. In several types of aggressive cancers including gastric, lung, and breast cancer, the aberrant expression and localization of $\beta$-catenin expression may trigger the weakening of cell-cell junctions and promote cell dedifferentiation, hyperproliferation, invasion and metastasis (24). Therefore, it is critical to understand the central role of the $\mathrm{Wnt} / \beta$-catenin signaling pathway and interaction between its target genes in the invasion and metastasis of gastric cancer. Previous studies have shown that KLF4 interacts with $\beta$-catenin and represses $\beta$-catenin-mediated gene expression, which plays an important role in maintaining homeostasis of the normal intestine, and is implicated in the regulation of stem cells and cancer progression $(27,28)$. However, a clear link between KLF4 and $\beta$-catenin in gastric cancer progression has not yet been demonstrated.

In the present study, we demonstrate a correlation between the expression levels of KLF4 and $\beta$-catenin. We also demonstrate that KLF4 expression plays a role in the inhibition proliferation, invasion and metastasis of gastric cancer in in vivo and in vitro models. Our results suggest that the anticancer properties of KLF4 are due to its ability to inhibit the $\beta$-catenin expression levels, which subsequently alters $\beta$-catenin signaling mechanisms.

\section{Materials and methods}

Cell culture and lentiviral infection. Human gastric cancer cell lines (MKN-28, BCG-823, SGC-7901 and MKN-45) were purchased from the cell bank of Chinese Academy of Sciences and cultured in RPMI-1640 medium (Gibco Biomedical, Carlsbad, CA, USA) supplemented with $10 \%$ fetal bovine serum (FBS) at $37^{\circ} \mathrm{C}$ in the presence of $5 \% \mathrm{CO}_{2}$. All gastric cancer cell line cultures were infected with the concentrated viral stocks of pLv-UbC-IRES2-KLF4-enhanced green fluorescent protein (EGFP) or pLv-UbC-IRES2-EGFP in RPMI-1640 for $8 \mathrm{~h}$ at $37^{\circ} \mathrm{C}$. The cell lines were renamed 28-KLF4, 28-EGFP, 823-KLF4, 823-EGFP, 7901-KLF4, 7901-EGFP, 45-KLF4, 45-EGFP after stable transduction with KLF4 or the control EGFP using a concentration of $3 \times 10^{5}$ transducing units/well for 24-well plates at a multiplicity of infection (MOI) of 50 . Over $95 \%$ cells infected with pLv-UbC-IRES2-KLF4-EGFP or pLv-UbC-IRES2-EGFP were green fluorescent protein (GFP)positive after $96 \mathrm{~h}$ of infection.

Quantitative real-time PCR. Total RNA isolation and real-time PCR were performed as previously described (29). Briefly, total RNA from the gastric cancer cell line was isolated according to the manufacturer's instructions for TRIzol ${ }^{\circledR}$ reagent (Takara, Dalian, China). RNA (1 $\mu \mathrm{g})$ was purified with DNase I (Takara) and then reverse-transcribed using SuperScript ${ }^{\mathrm{TM}}$ II Reverse Transcriptase (Takara), according to the manufacturer's instructions. Duplicates of the 4-fold serial dilution of cDNA samples were used in a 25-1 total volume containing 12.51 SYBR $^{\circledR}$-Green PCR master mix (Applied Biosystems, Foster City, CA, USA) and $300 \mathrm{nM}$ primers for each RT-PCR reaction. Amplification was performed in the 7300 Real-Time PCR System (Applied Biosystems). Cycle parameters were: $50^{\circ} \mathrm{C}(2 \mathrm{~min})$ and $95^{\circ} \mathrm{C}$ (10 min), followed by 38 cycles of $95^{\circ} \mathrm{C}(15 \mathrm{sec})$ and $60^{\circ} \mathrm{C}(1 \mathrm{~min})$, and a dissociation stage of $95^{\circ} \mathrm{C}(15 \mathrm{sec}), 60^{\circ} \mathrm{C}(30 \mathrm{sec})$ and $95^{\circ} \mathrm{C}$ $(15 \mathrm{sec})$. Fold inductions were calculated using the formula $2^{-(\Delta \Delta \mathrm{Ct})}$, where $\Delta \Delta \mathrm{Ct}$ was the $\Delta \mathrm{Ct}$ (stimulus) - $\Delta \mathrm{Ct}$ (control), $\Delta \mathrm{Ct}$ was $\mathrm{Ct}$ (KLF4, $\beta$-catenin) - Ct (GADPH) and $\mathrm{Ct}$ was the cycle at which the threshold was crossed. The gene-specific primer pairs are shown in Table I. PCR product quality was monitored by post-PCR melt curve analysis.

Flow cytometry. The effect of KLF4 overexpression on cell viability was assessed using flow cytometry after staining with propidium iodide and Annexin V-FITC (Roche) according to the manufacturer's instructions. Briefly, following KLF4 overexpression, cells were trypsinized and washed twice in ice-cold phosphate-buffered saline (PBS). A total of $1 \times 10^{6}$ cells were resuspended in $100 \mu \mathrm{l}$ binding buffer $(10 \mathrm{mM}$ HEPES/ $\mathrm{NaOH}$ pH 7.4, $140 \mathrm{mM} \mathrm{NaCl}, 2.5 \mathrm{mM} \mathrm{CaCl}_{2}$ ) to which was added $5 \mu 12 \mathrm{mg} / \mathrm{ml}$ Annexin V-FITC and $10 \mu 150 \mathrm{mg} / \mathrm{ml}$ propidium iodide. Following a 15 -min incubation in the dark, flow cytometry was performed using a CyAn ADP analyzer (Dako, Dublin, Ireland) using a 515/545-nm filter set for FITC detection and a 620/640-nm set for propidium iodide. The analysis was repeated in triplicates.

Western blot analysis. The following antibodies were used for western blot analysis: anti-KLF4 (rabbit polyclonal antibody, Abcam Biotechnology, Cambridge, UK), anti- $\beta$-catenin (mouse monoclonal antibody; Millipore Biotechnology, Billerica, MA, USA); anti-matrix metallopeptidase 2 (MMP2) (rabbit polyclonal antibody; Santa Cruz Biotechnology, Santa Cruz, CA, USA), anti-E-cadherin (rabbit polyclonal antibody; Santa Cruz Biotechnology), and anti- $\beta$-actin (mouse monoclonal; Santa Cruz Biotechnology). Cell lysates were minced and washed 3 times with ice-cold PBS. They were gently centrifuged and soaked in $500 \mathrm{ml}$ of hypotonic buffer $(1 \mathrm{mM} \mathrm{NaHCO})$ containing $2 \mathrm{mM}$ phenylmethanesulfonyl fluoride (PMSF) for $30 \mathrm{~min}$ and centrifuged at $15,000 \mathrm{x} \mathrm{g}$ for $15 \mathrm{~min}$. The supernatant was mixed with half its volume of 33 loading buffer [ $30 \%$ glycerol, $6 \%$ sodium-dodecylsulfate (SDS), $62.5 \mathrm{mM}$ Tris- $\mathrm{HCl}$, and $\mathrm{pH}$ 6.8]. The protein concentrations were measured with a 5000002 Protein Assay Kit II (Bio-Rad, Hercules, CA, USA). Before centrifugation, the protein was mixed with $750 \mu \mathrm{l}$ of loading buffer (10\% glycerol, 2\% SDS, $62.5 \mathrm{mM}$ Tris- $\mathrm{HCl}$, $\mathrm{pH}$ 6.8) and boiled for $5 \mathrm{~min}$ in the presence of 2-mercaptoethanol. A total of $50 \mu \mathrm{g}$ of each sample was electrophoresed on $10 \%$ SDS-polyacrylamide gels and transferred onto PVDF membranes (Millipore Biotechnology). The membranes were first blocked with $5 \%$ skim milk, then incubated with primary antibodies, followed by secondary antibodies coupled with horseradish peroxidase (HRP) (Amersham, Arlington Heights, 
Table I. Primer sequences of KLF4 and $\beta$-catenin and their qRT-PCR products.

\begin{tabular}{|c|c|c|c|}
\hline Gene & & Primer sequence & Product size \\
\hline KLF4 & $\begin{array}{l}\text { Forward } \\
\text { Reverse }\end{array}$ & $\begin{array}{l}\text { 5'-TCGGACCACCTCGCCTTACA-3' } \\
\text { 5'-CTGGGCTCCTTCCCTCATCG-3' }\end{array}$ & 133 bp \\
\hline$\beta$-catenin & $\begin{array}{l}\text { Forward } \\
\text { Reverse }\end{array}$ & $\begin{array}{l}\text { 5'-CCAAGTGGGTGGTATAGAGG-3' } \\
\text { 5'-AGTCCATAGTGAAGGCGAAC-3' }\end{array}$ & $156 \mathrm{bp}$ \\
\hline GADPH & $\begin{array}{l}\text { Forward } \\
\text { Reverse }\end{array}$ & $\begin{array}{l}\text { 5'-ATCAAGAAGGTGGTGAAGCAGG-3' } \\
\text { 5'-AAGGTGGAGGAGTGGGTGTCG-3' }\end{array}$ & 113 bp \\
\hline
\end{tabular}

KLF4, Krüppel-like factor 4.

IL, USA), and finally visualized with an enhanced chemiluminescence (ECL) reagent.

MTT assay. For cell proliferation assay, $2 \times 10^{3}$ cells/well were plated in triplicates in 24-well plates and cell proliferation was evaluated on days $1,2,3,4,5,6$ and 7. The proliferation of the KLF4 overexpressing cell line, $45-\mathrm{KLF} 4$, was represented as a percentage of the cell count compared to the control cell line, MKN-45, set at $100 \%$ proliferation. The mean values from 3 different experiments were calculated to represent the proliferation difference.

Colony formation assays. To examine the effects of up-regulated KLF4 expression on the proliferation of gastric cancer cells, 45-KLF4 cells were used for colony formation assay as described previously $(30,31)$ with MKN-45 cells as the control group. The cells were seeded onto 24 -well plates $(2,000$ cells/ well) and cultured for 2 weeks in RPMI-1640 medium containing 10\% FBS. These cultures were washed twice with PBS, fixed with $4 \%$ paraformaldehyde for $15 \mathrm{~min}$, dried at room temperature, and stained with Giemsa (Sigma-Aldrich, St. Louis, MO, USA). Clones larger than $2 \mathrm{~mm}$ were counted manually and the number of clones per well was averaged from 3 wells for each experiment, with 3 independent experiments performed.

Transwell migration and invasion assays. Cell migration and invasion assays were performed as described previously $(32,33)$, using $8.0 \mu \mathrm{m}$ pore size polycarbonate membrane transwell inserts in a 24 -well plate. MKN-45 (control), and 45-KLF4 cells $\left(2 \times 10^{5}\right)$ were plated on the upper well of a Matrigel invasion chamber in a 24-well chamber that contained RPMI1640 medium with 5\% FBS. The lower side of the separating filter was filled with RPMI-1640 medium with $20 \%$ FBS. The chamber was incubated in a tissue culture incubator, and after $24 \mathrm{~h}$, cells on the upper surface (non-migrated cells) were removed by scrubbing with a cotton swab, and the cells remaining on the filter were fixed with $4 \%$ paraformaldehyde for $15 \mathrm{~min}$, dried at room temperature, stained with Giemsa (Sigma-Aldrich, St. Louis, MO, USA) and manually counted. The cells that successfully migrated through the filter were photographed. At least 5 different $\times 400$ magnification fields were counted for each experiment, and the results were averaged over 3 independent experiments. Invasion assays were performed as described above using BD Matrige ${ }^{\mathrm{TM}}$ Invasion Chambers (BD Biosciences, Franklin Lakes, NJ, USA) as per the manufacturer's instructions.

Tumorigenicity assay in nude mice. The inhibition of tumor growth and tumorigenicity assay due to KLF4 forced expression was performed as previously described $(30,34)$. BALB/c nude mice (4-6 weeks old) were obtained from the Department of Laboratory Animal Science, Chongqing University Health Science Center. All procedures were carried out according to the animal protocol approved by the Institutional Animal Care and Use Committee of the Chongqing Medical University. 45-KLF4 and MKN-45 (control) cells were trypsinized, washed in PBS, resuspended in saline solution, and $5 \times 10^{6}$ cells per $0.2 \mathrm{ml}$ were injected subcutaneously into each nude mouse (at least 6 mice in each experimental group). The tumor size was measured every third day. The tumor volume was calculated according to the formula $\mathrm{V}=\left(\mathrm{a} \mathrm{x} \mathrm{b}^{2}\right) / 2$, where $\mathrm{a}=$ the largest superficial diameter and $b=$ the smallest superficial diameter. After 3 weeks, the mice were sacrificed and the tumors were collected and photographed.

Statistical analysis. All data are presented as the means \pm SEM. The significance of differences was determined using the Student's t-test, and analysis of variance (ANOVA) and appropriate post hoc tests were used when comparing multiple parameters. $\mathrm{P}<0.05$ was considered to indicate statistically significant differences.

\section{Results}

KLF4 and $\beta$-catenin expression in parental gastric cancer cell lines. In order to identify a suitable cell line for further analysis of KLF4 function and the association between KLF4 and $\beta$-catenin, KLF4 and $\beta$-catenin mRNA and protein expression levels were examined in parental gastric cancer cell lines. A high variability of KLF4 expression was observed for these cells lines (Fig. 1). Specifically, levels of KLF4 mRNA (Fig. 1B-1) and protein (Fig. 1C-1) expression were lowest in the MKN-45 cells. Simultaneously, we examined the level of $\beta$-catenin expression in the same cell line. By contrast, the expression levels of $\beta$-catenin mRNA (Fig. 1B-2) and protein (Fig. 1C-2) were highest in the MKN-45 cells. Therefore, the MKN-45 cell line was selected for further analysis. 


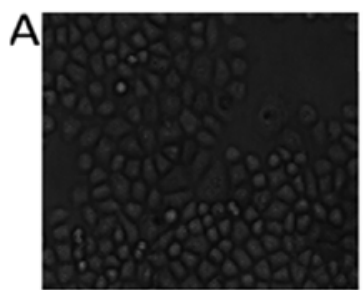

MKN-45

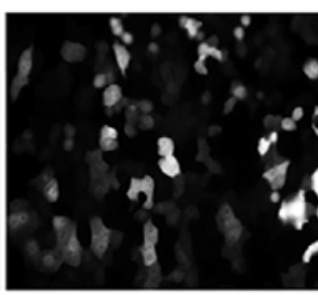

SGC-7901

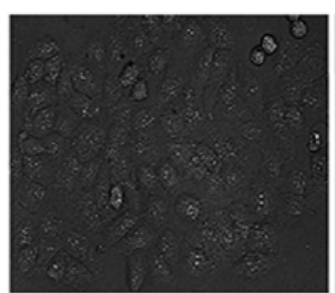

BCG-823

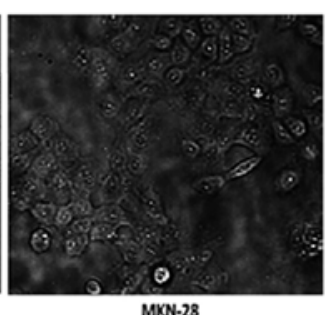

MKN-28
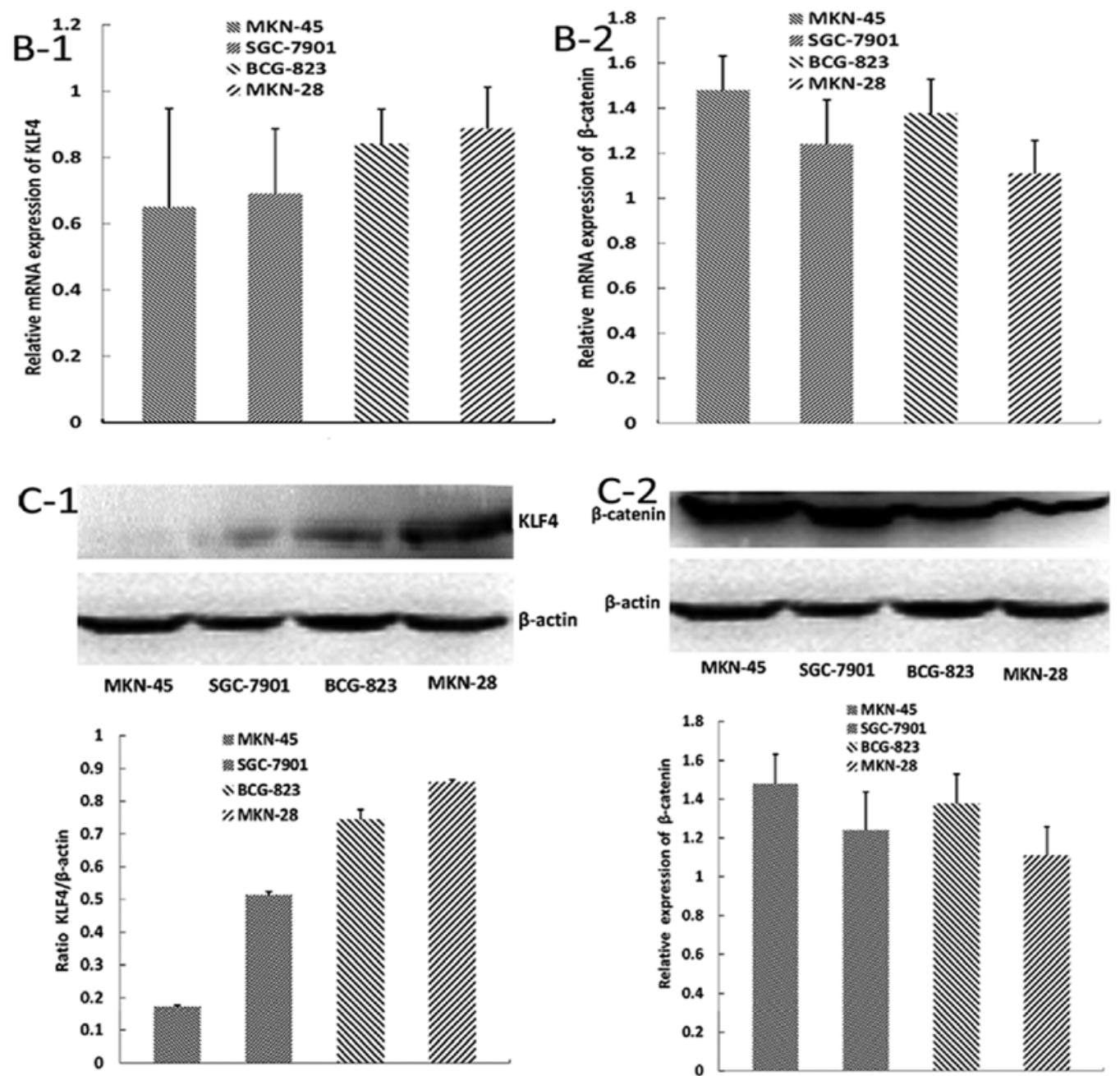

Figure 1. The mRNA and protein expression levels of KLF4 and $\beta$-catenin in parental gastric cancer cell lines. (A) Representative images of parental gastric cancer cells (x200). (B) Abnormal mRNA expression of KLF4 (B-1) and $\beta$-catenin (B-2). (C) Decreased expression of the KLF4 protein (C-1), and high levels of the $\beta$-catenin protein (C-2). The protein levels were consistent with the relative mRNA expressions. KLF4, Krüppel-like factor 4.

Evaluation of KLF4 and $\beta$-catenin expression in $M K N-45$ and 45-EFGP cells. The expression levels of KLF4 and $\beta$-catenin were evaluated in the parental gastric cancer cells that were treated with the empty lentviral vector, MKN-45 (control untransduced) and 45-EFGP (transduced) cells. As shown in Fig. 2, there was no statistical difference in the mRNA and protein levels of KLF4 and $\beta$-catenin in the 45-EFGP cells compared to the parental MKN-45 cell line. Therefore, cells treated with the empty lentviral vector were omitted in the subsequent experiments.

Examination of the association between KLF4 and $\beta$-catenin expression in KLF4-overexpressing gastric cancer cell lines. To clarify the association between KLF4 and $\beta$-catenin expres- sion levels after successfully restoring the expression of KLF4, the mRNA and protein expression of KLF4 and $\beta$-catenin in the parental gastric cancer cell lines and the transduced cell lines, 28-KLF4, 823-KLF4, 7901-KLF4 and 45-KLF4, were examined. A high variability in KLF4 expression among these cell lines after lentiviral infection was observed (Fig. 3B-1 and C-1). Specifically, the levels of KLF4 mRNA and protein expression were highest in the 45-KLF4 cells. However, mRNA and protein levels of $\beta$-catenin decreased in the KLF4expressing cells (Fig. 3B-1 and C-1).

KLF4 overexpression inhibits proliferation, colony formation, invasion and migration. To investigate the effects of KLF4 overexpression in gastric cancer cells, cell cycle, proliferation, 

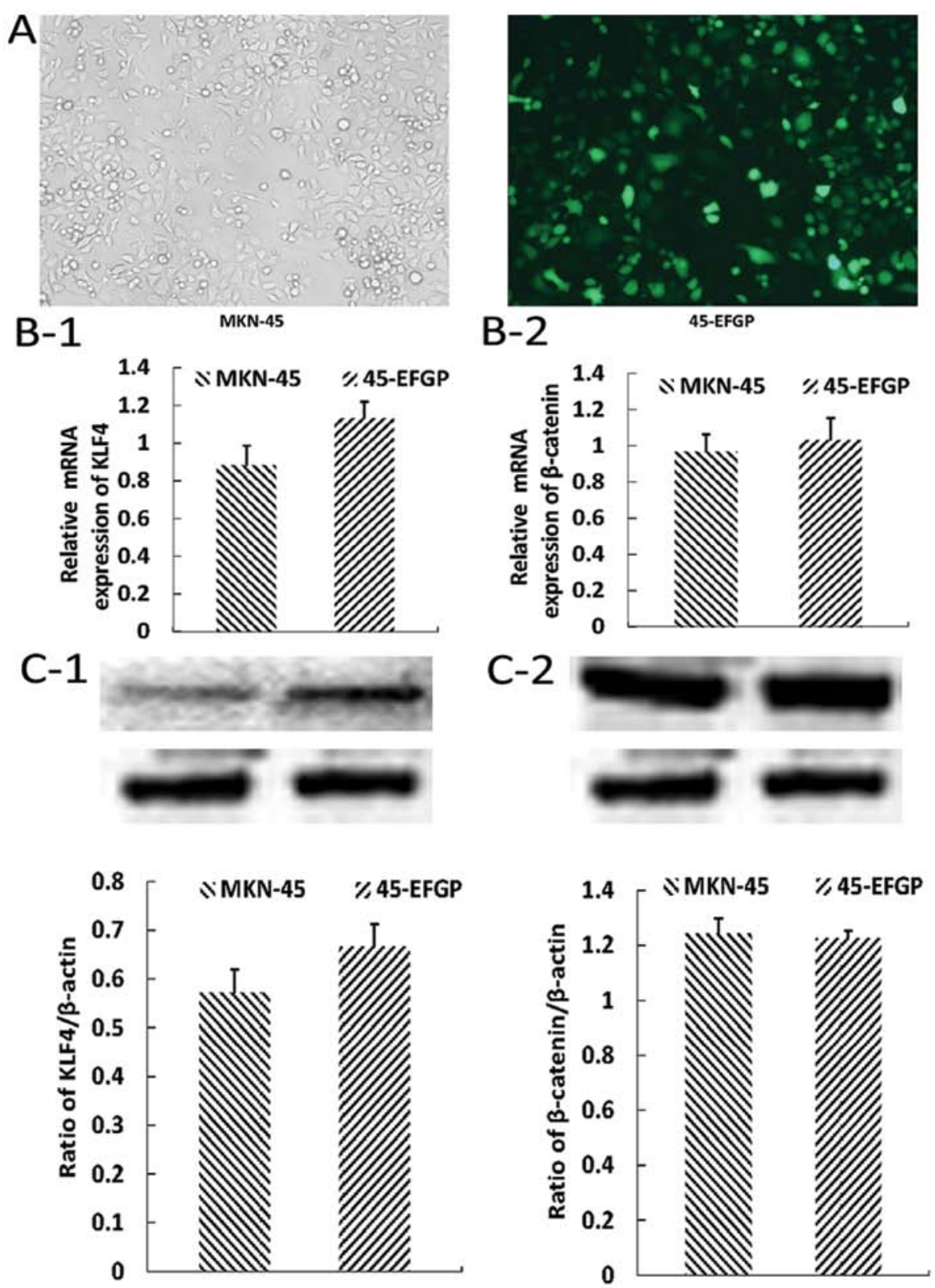

Figure 2. Expression of mRNA and protein of KLF4 and $\beta$-catenin in MKN-45 and 45-EFGP cells. (A) Representative images of MKN-45 cells (left) and 45-EFGP cells (right), (x200). (B) mRNA expression of KLF4 (B-1) and $\beta$-catenin (B-2). (C) Protein expression of KLF4 (C-1) and $\beta$-catenin (C-2). KLF4, Krüppel-like factor 4.

colony formation, invasion and migration in vitro were evaluated in the MKN-45 and 45-KLF4 cell lines. Compared with the MKN-45 cells, 45-KLF4 cells showed a 7-fold G1-block in the cell cycle (Fig. 4A). A significant difference in the percentage between MKN-45 and 45-KLF4 cells in the subG1 population was observed. $45-\mathrm{KLF} 4$ cells displayed a $61.8 \pm 0.0068 \%$ inhibition of proliferation compared to MKN-45 cells, as determined by MTT assay (Fig. 4B). Consistent with reduced proliferation, the colony formation capability of 45-KLF4 cells was significantly weaker in comparison with the parental MKN-45 cells. As shown in Fig. 3C, 45-KLF4 cells showed an almost 12 -fold inhibition of colony formation $(\mathrm{P}<0.05)$. The majority of clones from 45-KLF4 cells were significantly smaller than those of the parental MKN-45 cells. To deter- mine whether the ability of invasion and metastases decreased in the 45-KLF4 cells, a transwell experiment was performed to assess the invasion and metastatic ability of the 45-KLF4 cell line compared to the MKN-45 cell line (Fig. 4D). To compare the migratory capacity of the MKN-45 cells, we found that 45-KLF4 cell lines exhibited significantly decreased migration and invasion, the 45-KLF4 cells being 4-fold less invasive $(\mathrm{P}<0.05)$ (Fig. 4D). Similarly, the overexpression of KLF4 in 45-KLF4 cells inhibited cell invasion compared to the MKN-45 control cells $(\mathrm{P}<0.05)$. Cell migration showed a similar profile (data not shown). Taken together, these results suggest that enhanced KLF4 expression plays a role in the suppression of the cell cycle, proliferation, colony formation, invasion and migration in gastric cancer cells in vitro. 

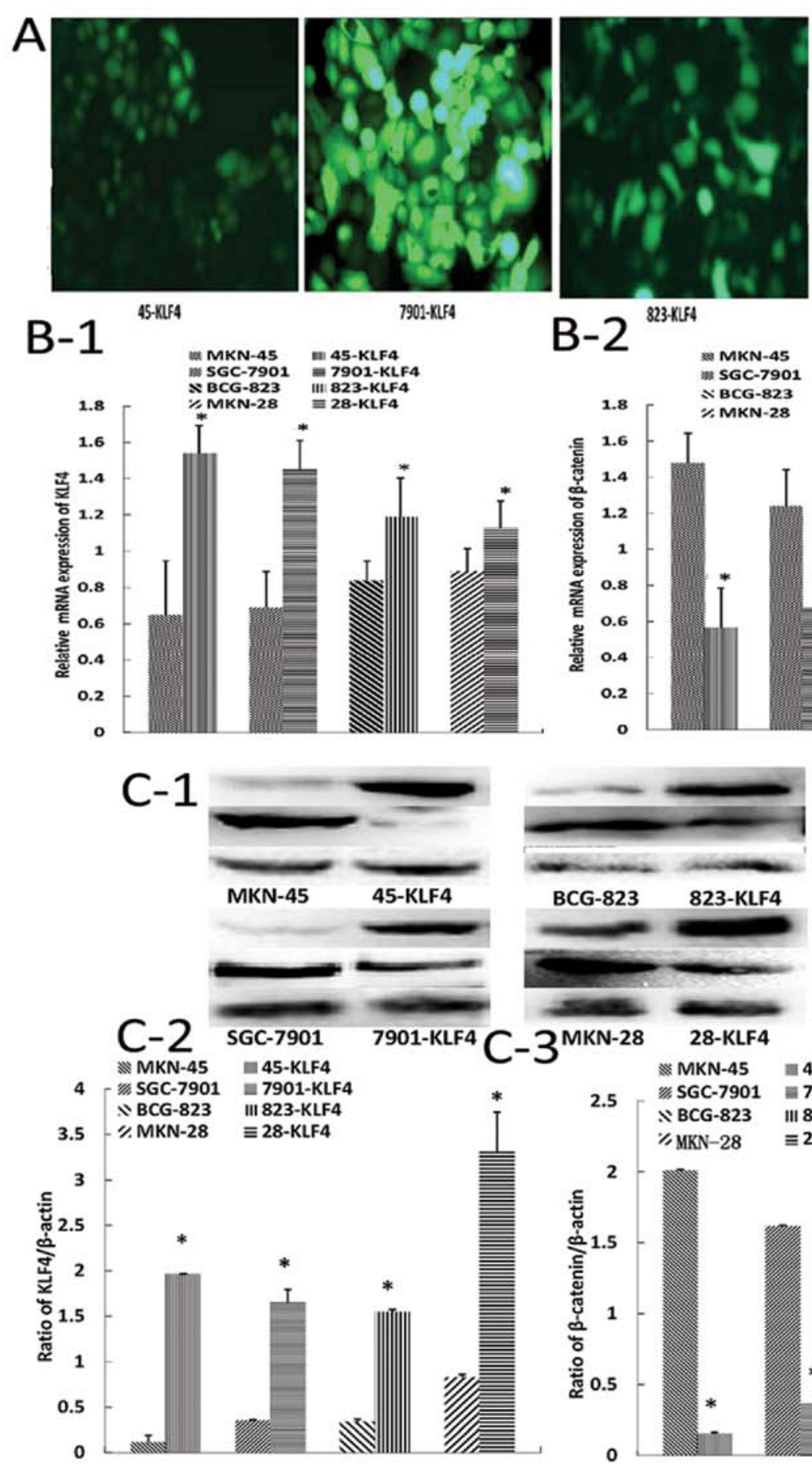

B-2 23304
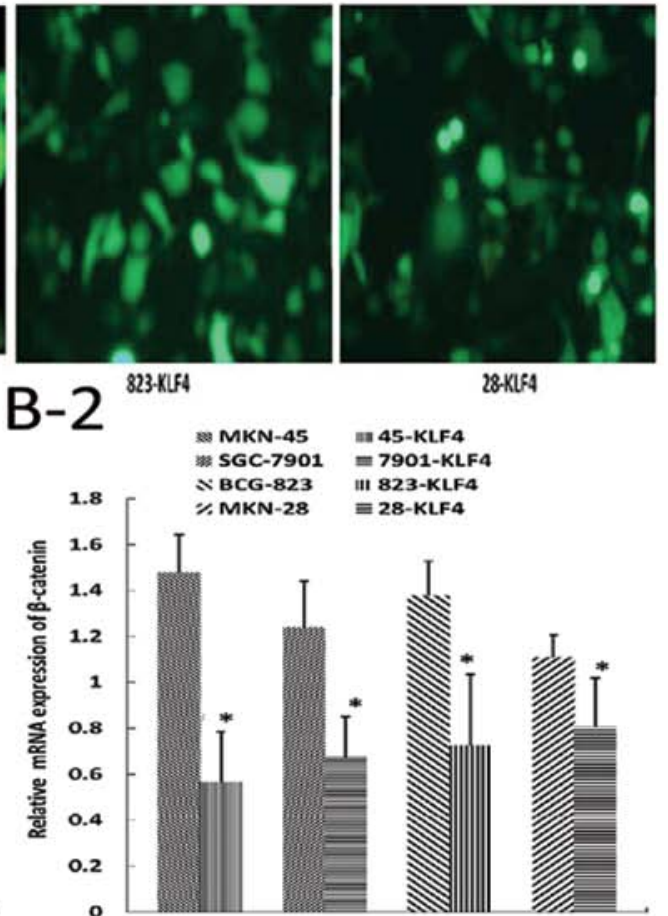

28-KIF4
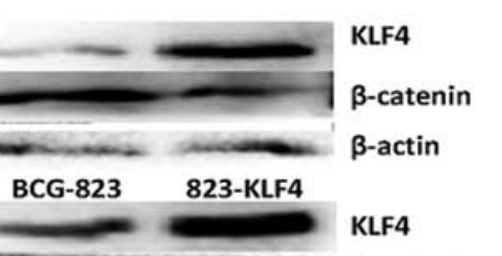

arasanin
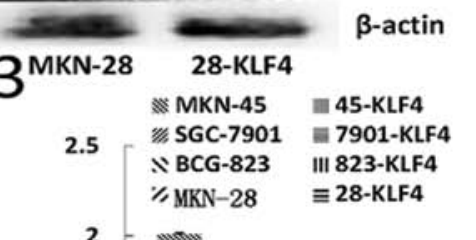

-actin

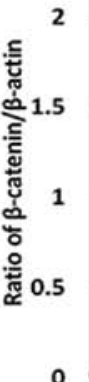

0

Figure 3. (A) Representative images of KLF4 overexpression in gastric cancer cells, (x200). (B) The expression of KLF4 mRNA (B-1) significantly increased, but levels of $\beta$-catenin mRNA (B-2) decreased. (C) KLF4 protein (C-1 and C-2) levels notably increased in stably transfected cells, but the protein level (C-1, C-3) of $\beta$-catenin decreased; these results were consistent with the mRNA levels. ${ }^{*} \mathrm{P}<0.05$, compared with parental cells. KLF4, Krüppel-like factor 4.

Enhanced expression of KLF4 restores E-cadherin expression and inhibits MMP2 expression. A previous study has indicated that KLF4 prevents the metastasis of breast cancer through the up-regulation of E-cadherin expression (33). In a similar fashion, the enhanced expression of KLF4 in the 45-KLF4 cells resulted in the up-regulation of E-cadherin expression and decreased MMP2 expression (Fig. 5). In the parental MKN-45 cells which have low KLF4 and higher $\beta$-catenin expression levels, we observed the opposite pattern with decreased
E-cadherin and elevated MMP2 expression levels (Fig. 5). These results support the concept that KLF4 positively regulates E-cadherin expression and inhibits MMP2 expression in gastric cancer cells.

KLF4-mediated inhibitory effects on gastric cancer in vivo. The inhibitory effect of KLF4 overexpression on tumor growth was analyzed in 45-KLF4 cells in vivo. There were at least 6 nude mice in the MKN-45 and 45-KLF4 treatment groups. 

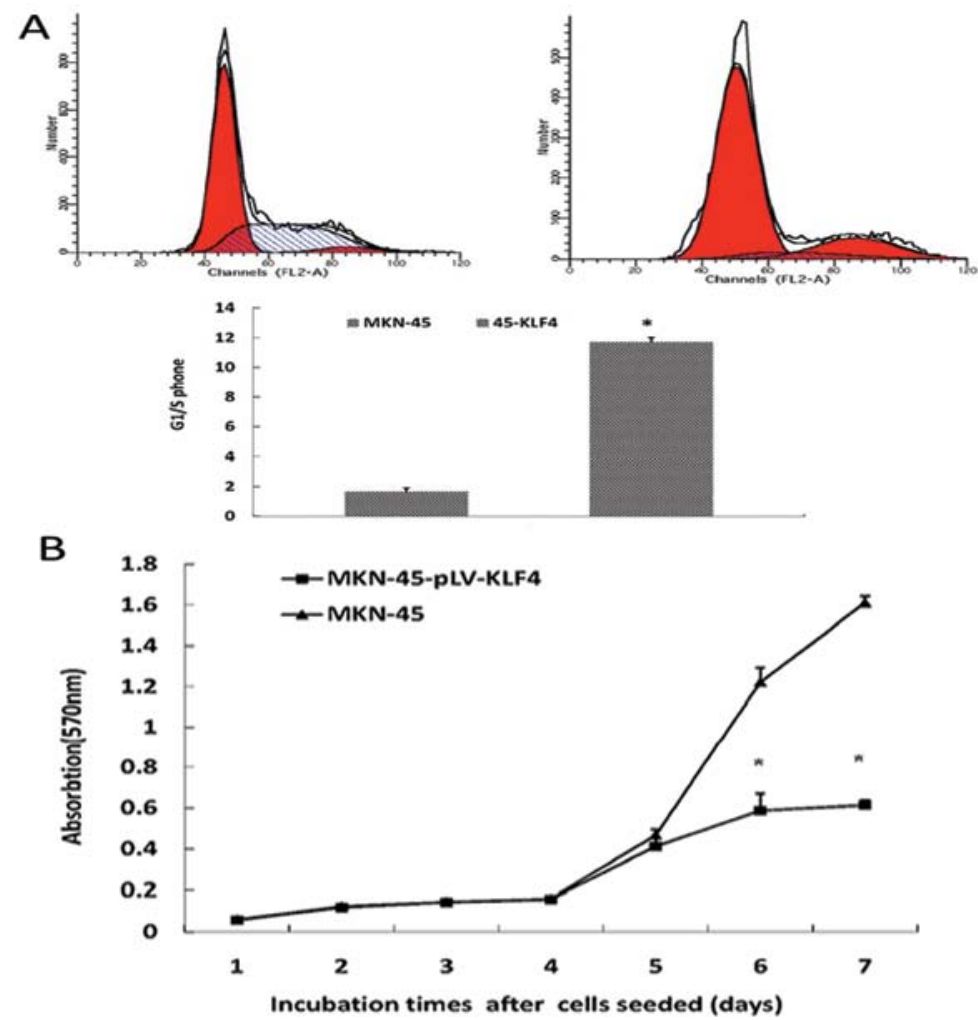

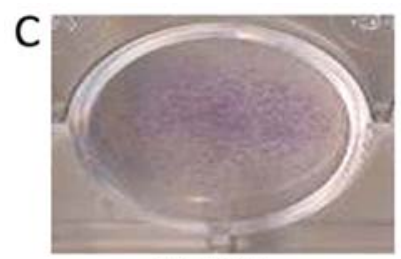

MKN-45
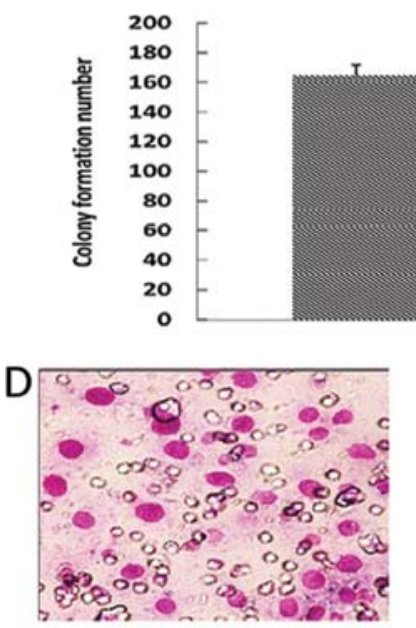

MKN-45

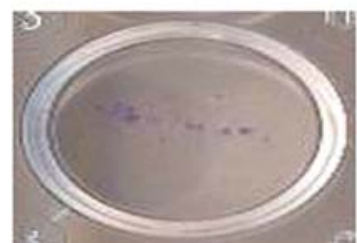

45-KLF4

MKN-45

45-KLF4

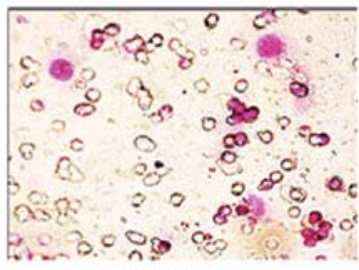

45-KLF4

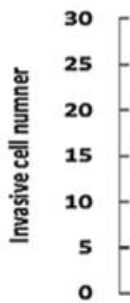

MKN-45

\% 45-KLF4

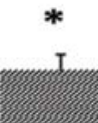

Figure 4. Inhibitory effects of KLF4 overexpression inhibited growth of gastric cancer cells in vitro. (A) Forced expression of KLF4 induced G1/S arrest. "P $<0.05$ compared with MKN-45 cells. (B) Growth curves of cells plotted by the MTT assay and the inhibition rate of cell proliferation by KLF4; ${ }^{*} \mathrm{P}<0.05$ compared with MKN-45 cells. (C) Analysis of colony formation numbers, "P $<0.05$ versus the control group. (D) Representatives photomicrographs ( $x 400$ ) of cell invasion. The mean number of cells was summarized. "P<0.05 versus the parental cells. KLF4, Krüppel-like factor 4. 


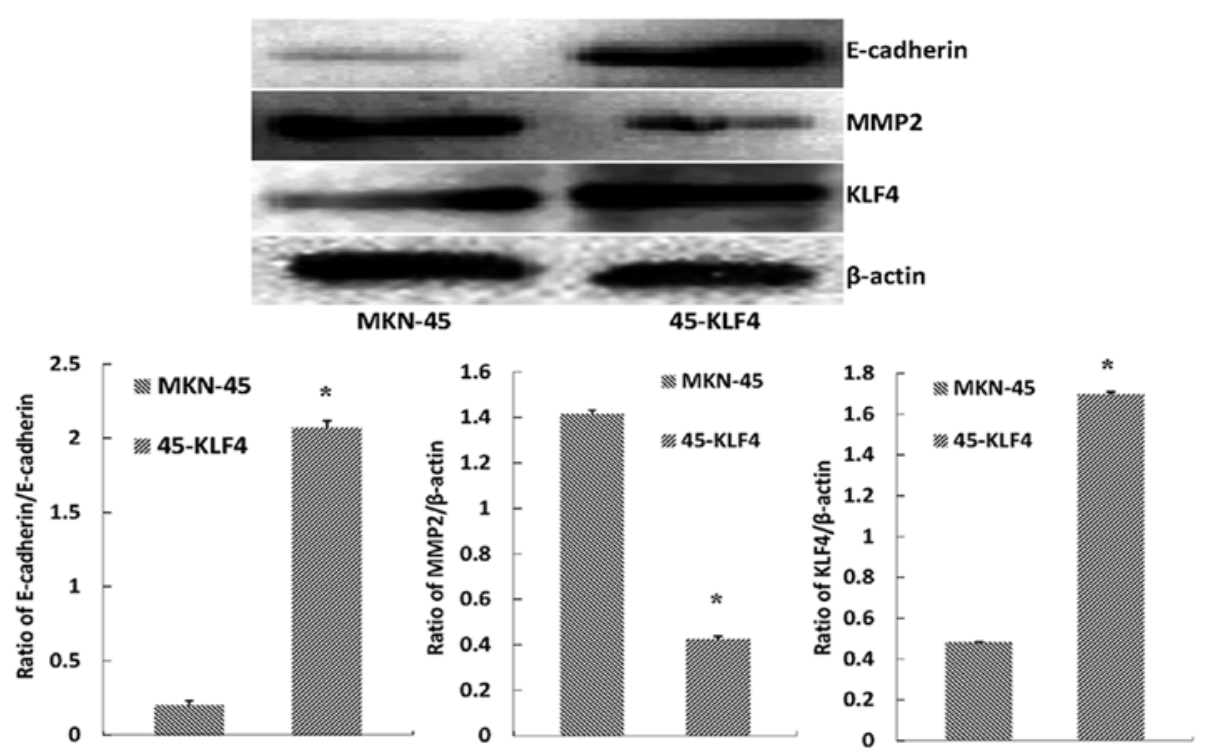

Figure 5. KLF4 is required to sustain E-cadherin expression and inhibit MMP2 expression in gastric cancer cells. (A) Western blot analysis of KLF4, E-cadherin and MMP2. (B) Values are the means \pm SD, ${ }^{*}$ different from MKN-45 cells; (B-1) increased E-cadherin expression in 45-KLF4 cells, ${ }^{*} \mathrm{P}<0.05$ versus the control group; (B-2) restored KLF4 expression sharply decreased MMP2 expression, "P<0.05 versus the control group; (B-3) KLF4 expression was significantly increased in 45-KLF4 cells compared with MKN-45 cells ( $\mathrm{P}<0.05)$. KLF4, Krüppel-like factor 4.

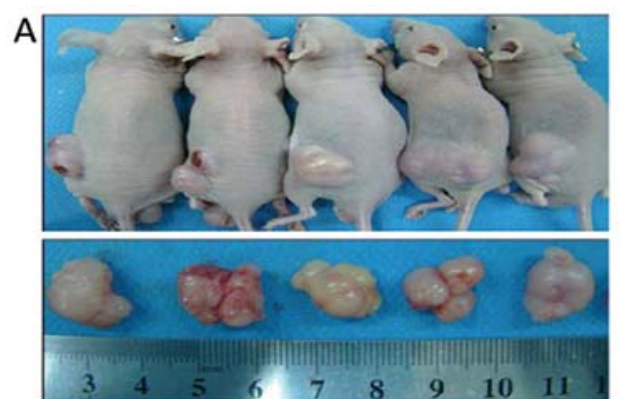

B-1

MKN-45

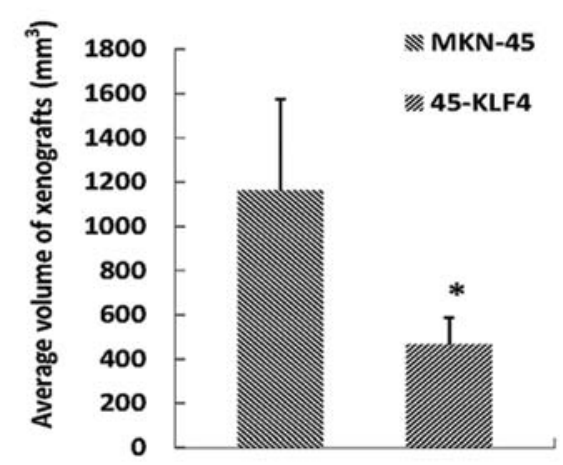

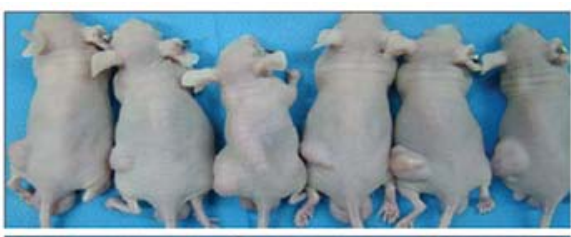

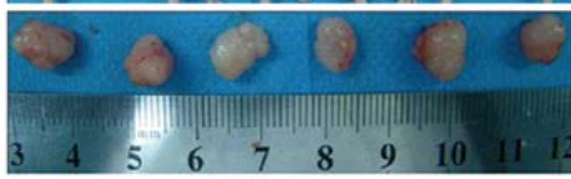

B-2

45-KLF4

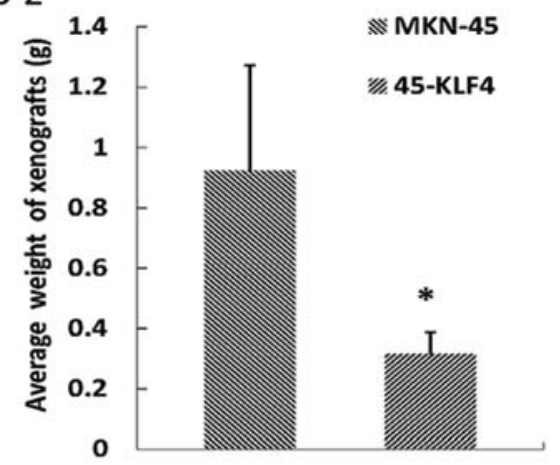

Figure 6. Suppression of tumor growth by KLF4 in vivo. (A) Images of tumor growth in MKN-45 and 45-KLF4 cells. (B) Compared with the control group, the average volume (B-1) and weight (B-2) of the xenografts were significantly smaller ("P<0.05), consistent with the findings in vitro, that restoring KLF4 gene expression suppresses tumor growth in vivo. KLF4, Krüppel-like factor 4.

One mouse died prematurely in the control group. MKN-45 and $45-$ KLF4 cells $\left(5 \times 10^{6}\right)$ were inoculated subcutaneously into the rear flanks of nude mice. Observation of tumor growth was performed at 3-day intervals. As described in Fig. 6, the tumor growth of 45-KLF4 cells was dramatically retarded compared with the parental MKN-45 cells. At the termination of the experiment, the mean size of KLF4-expressing tumors was significantly smaller than that of the parental MKN-45 cells $(\mathrm{P}<0.05)$ (Fig. 6).

\section{Discussion}

KLF4 (also known as Gut-enriched Krüppel-like factor) is an important member of the zinc finger-containing transcription 
factor family (35). The Krüppel-like factor family, including $\mathrm{KLF} 4$, is characterized by 3 zinc-finger domains in its C-terminus (36). Depending on the molecular environment, KLF4 acts as either a tumor suppressor gene or an oncogene (37). High expression levels of KLF4 are present in normal gastrointestinal epithelial cells, which are associated with growth arrest, cell proliferation and late-stage cell differentiation $(14,38)$. However, KLF4 expression levels have been shown to be significantly reduced in a number of cancer types $(16,19,39-42)$ and tumor size has been shown to negatively correlate with KLF4 expression levels $(43,44)$. Alterations in KLF4 expression levels lead to aberrant proliferation and differentiation in the gastric epithelium (45). Accumulating evidence has suggested that KLF4 is a putative tumor suppressor in the digestive tract. KLF4 knockout mice display defects in gastric cell differentiation and precancerous changes in the stomach $(19,45)$. In addition, the forced expression of KLF4 in colon cancer cell lines induces colon cancer cell growth arrest (14), and represses $\beta$-catenin transcription (46). These results suggest that KLF4 is a tumor suppressor participating in the progression and development of gastric tumors. In our current study, we discovered that KLF4 mRNA and protein expression was low in parental gastric cancer cell lines by qRT-PCR and western blot analysis (Fig. 1). However, KLF4 mRNA and protein levels increased after stable overexpression of KLF4, when compared with parental cells (Fig. 2; $\mathrm{P}<0.05$ ).

Over the years, $\beta$-catenin has been recognized not only for mediating intercellular adhesion (20), but also for its role in the regulation of cell growth, differentiation, invasion and metastasis (24). $\beta$-catenin is a key downstream molecule in the Wnt signaling pathway and binds to TCF/LEF. The $\beta$-catenin-TCF/ LEF complex regulates and activates its downstream target transcription genes which are involved in development, tissue self-renewal and cancer (47), and plays a pivotal role in intracellular signaling and represents a key element in one of the most important pathways of epithelial carcinogenesis $(22,48)$.

$\beta$-catenin has been recognized as an oncogene in a variety of tumors $(25,49)$. In many types of aggressive and lethal cancers, aberrant $\beta$-catenin expression may weaken the cellcell junctions and promote carcinoma cell dedifferentiation, hyperproliferation, invasion and metastasis. This feature is commonly found in gastric cancer tumors (50). Previous studies have confirmed that high $\beta$-catenin expression is an independent indicator of poor prognosis for these carcinomas and closely correlates with enhanced tumor progression $(49,51)$. In this study, we found that the expression of $\beta$-catenin was increased notably in both mRNA and protein gastric cancer cell lines with different gastric cancer cell differentiation stages (Fig. 1). However, the mRNA (Fig. 3B-2) and protein (Fig. 3C-1 and C-3) expression levels of $\beta$-catenin decreased significantly in the cell lines with enhanced KLF4 expression, when compared with the parental cells (Fig. 3).

In this study, we investigated whether the zinc-finger transcription factor, KLF4, plays a role in the inhibition of invasion and metastasis of gastric cancer by identifying its upstream regulators and downstream target genes, and characterizing its effects on gastric cancer cells. It is possible that the functional activation or inhibition of KLF4 may be determined not only by the activation status of its upstream genes, but also through a complex interplay of both positive and negative downstream target genes. Our results strongly suggest that KLF4 is an important negative regulator of $\beta$-catenin expression in gastric cancer cells, for the following reasons: i) KLF4 and $\beta$-catenin expression were mutually exclusive in parental gastric cancer cell lines (for example, we observed a markedly reduced expression of KLF4 but the expression levels of $\beta$-catenin were abnormally increased); ii) the enhanced expression of KLF4 in the gastric cancer cell line, MKN-45, resulted in a significant increase in KLF4 at both the mRNA and protein levels, while the mRNA and protein expression of $\beta$-catenin were sharply decreased in the same cell lines; iii) in the KLF4-overexpressing cells (with low activity of $\beta$-catenin), many biological characteristics of gastric cancer were inhibited. These findings show that the reduced expression of KLF4 contributes to the inhibition of $\beta$-catenin expression in human gastric cancer cell lines. To our knowledge, this is the first report demonstrating that KLF4 negatively inhibits the activity of $\beta$-catenin in gastric cancer cell lines and regulates the malignant transformation of gastric cancer.

It is intriguing that the zinc-finger transcription factor, KLF4, regulates the invasion and metastasis-related genes, such as E-cadherin and MMP2. E-cadherin is a major component of the Wnt/ $\beta$-catenin signal pathway and is an important effector of the E-cadherin/ $\beta$-catenin complex that mediates intercellular adhesion (20). Thus, it is considered a hallmark of epithelial cell phenotype. Recent evidence supports the hypothesis that E-cadherin is a bona fide KLF4-regulated gene (33). In gastric cancer patients, decreased E-cadherin expression in tumors is associated with advanced stage, lymph node-positive metastasis and aggressiveness (52). We found that E-cadherin protein expression levels were down-regulated, but the level of MMP2 protein was high in gastric cancer parental cell lines. When KLF4 was overexpressed, the expression pattern of E-cadherin and MMP2 was reversed. A potential mechanism for the anti-invasive and metastatic effects was that KLF4 enhanced expression caused the up-regulation of E-cadherin expression while down-regulating MMP2 expression, two important invasion and metastasis-related genes (Fig. 5). Our results suggest that the metastasis-associated genes, E-cadherin and MMP2, are highly dependent upon KLF4 overexpression, and that KLF4 can affect metastasis in gastric cancer by regulating metastasis-mediated genes.

The results of MTT and flow cytometry assay, colony formation and transwell assay indicate that the up-regulation of KLF4 inhibits gastric cancer cell proliferation, colony formation and invasiveness (Fig. 4). Importantly, the anti-invasive effects of KLF4 observed in vitro (Fig. 6) were highly consistent with its in vivo expression pattern in primary human tumors. Moreover, KLF4 expression could also be reactivated in the Wnt/B-catenin-hyperactive gastric cancer cell lines MKN-45 by modulation of $\beta$-catenin expression levels, indicating that KLF4 expression is determined by complex interactions between signaling pathways.

Taken collectively, the results confirm that $\mathrm{Wnt} / \beta$-catenin signaling is active and plays a key role in the progression of cell proliferation, dedifferentiation, invasion and metastasis. In summary, the enhanced expression of KLF4 inhibits invasion and metastasis of gastric cancer by negatively regulating the expression of $\beta$-catenin and subsequently $\beta$-catenin signaling mechanisms. 


\section{Acknowledgements}

This study was supported by grants from the 2010 annual medical research projects of the Chongqing Municipal Health Bureau (No. 2010-1-19). We thank the Key Laboratory of General Surgery Chongqing Medical University for providing the equipment.

\section{References}

1. Parkin DM, Bray F, Ferlay J and Pisani P: Global cancer statistics, 2002. CA Cancer J Clin 55: 74-108, 2005.

2. Zheng L, Wang L, Ajani J and Xie K: Molecular basis of gastric cancer development and progression. Gastric Cancer 7: 61-77, 2004.

3. Aurello P,D'Angelo F, Rossi S, Bellagamba R, Cicchini C,Nigri G, Ercolani G, De Angelis R and Ramacciato G: Classification of lymph node metastases from gastric cancer: comparison between $\mathrm{N}$-site and Number systems. Our experience and review of the literature. Am Surg 73: 359-366, 2007.

4. Saito H, Fukumoto Y, Osaki T, Yamada Y, Fukuda K, Tatebe S, Tsujitani S and Ikequchi M: Prognostic significance of the ratio between metastatic and dissected lymph nodes (n ratio) in patients with advanced gastric cancer. J Surg Oncol 97: 132-135, 2008.

5. Gou HF, Chen XC, Zhu J, Jiang M, Yang Y, Cao D and Hou M: Expressions of COX-2 and VEGF-C in gastric cancer: correlations with lymphangiogenesis and prognostic implications. J Exp Clin Cancer Res 30: 14, 2011.

6. Tahara E: Molecular aspects of invasion and metastasis of stomach cancer. Verh Dtsch Ges Pathol 84: 43-49, 2000.

7. Sud R, Wells D, Talbot IC and Delhanty JD: Genetic alterations in gastric cancers from British patients. Cancer Genet Cytogenet 126: 111-119, 2001.

8. Segre JA, Bauer C and Fuchs E: Klf4 is a transcription factor required for establishing the barrier function of the skin. Nat Genet 22: 356-360, 1999.

9. Panigada M, Porcellini S, Sutti F, Doneda L, Pozzoli O, Consalez GG, Guttinger M and Grassi F: GKLF in thymus epithelium as a developmentally regulated element of thymocyte-stroma cross-talk. Mech Dev 81: 103-113, 1999.

10. Yet SF, McA'Nulty MM, Folta SC, Yen HW, Yoshizumi M, Hsieh CM, Layne MD, Chin MT, Wang H, Perrella MA, Jain MK and Lee ME: Human EZF, a Krüppel-like zinc finger protein, is expressed in vascular endothelial cells and contains transcriptional activation and repression domains. J Biol Chem 273: 1026-1031, 1998.

11. Shields JM, Christy RJ and Yang VW: Identification and characterization of a gene encoding a gut-enriched Krüppel-like factor expressed during growth arrest. J Biol Chem 271: 20009-20017, 1996.

12. Jenkins TD, Opitz OG, Okano J and Rustgi AK: Transactivation of the human keratin 4 and Epstein-Barr virus ED-L2 promoters by gut-enriched Krüppel-like factor. J Biol Chem 273: 10747- 10754, 1998.

13. Garrett-Sinha LA, Eberspaecher H, Seldin MF and de Crombrugghe B: A gene for a novel zinc-finger protein expressed in differentiated epithelial cells and transiently in certain mesenchymal cells. J Biol Chem 271: 31384-31390, 1996.

14. Chen X, Johns DC, Geiman DE, Marban E, Dang DT, Hamlin G, Sun R and Yang VW: Krüppel-like factor 4 (gut-enriched Krüppellike factor) inhibits cell proliferation by blocking G1/S progression of the cell cycle. J Biol Chem 276: 30423-30428, 2001.

15. Jiang J, Chan YS, Loh YH, Cai J, Tong GQ, Lim CA, Robson P, Zhong $\mathrm{S}$ and $\mathrm{Ng} \mathrm{HH}$ : A core KLF circuitry regulates self-renewal of embryonic stem cells. Nat Cell Biol 10: 353-360, 2008.

16. Zhao W, Hisamuddin IM, Nandan MO, Babbin BA, Lamb NE and Yang VW: Identification of Kruppel-like factor 4 as a potential tumor suppressor gene in colorectal cancer. Oncogene 23: 395-402, 2004.

17. Wang N, Liu ZH, Ding F, Wang XQ, Zhou CN and Wu M: Downregulation of gut-enriched Kruppel-like factor expression in esophageal cancer. World J Gastroenterol 8: 966-970, 2002.

18. Foster KW, Ren S, Louro ID, Lobo-Ruppert SM, Mckie-Bell P, Grizzle W, Hayes MR, Broker TR, Chow LT and Ruppert JM: Oncogene expression cloning by retroviral transduction of adenovirus E1A-immortalized rat kidney RK3E cells: transformation of a host with epithelial features by c-Myc and the zinc finger protein GKLF. Cell Growth Differ 10: 423-434, 1999.
19. Wei D, Gong W, Kanai M, Schlunk C, Wang L, Yao JC, Wu TT, Huang $\mathrm{S}$ and Xie K: Drastic down-regulation of Krüppel-like factor 4 expression is critical in human gastric cancer development and progression. Cancer Res 65: 2746-2754, 2005.

20. Ozawa M, Ringwald M and Kemler R: Uvomorulin-catenin complex formation is regulated by a specific domain in the cytoplasmic region of the cell adhesion molecule. Proc Natl Acad Sci USA 87: 4246-4250, 1990.

21. Hoppler S and Kavanagh CL: Wnt signalling: variety at the core. J Cell Sci 120: 385-393, 2007.

22. Kanwar SS, Yu Y, Nautiyal J, Patel BB and Majumdar AP: The Wnt $/ \beta$-catenin pathway regulates growth and maintenance of colonospheres. Mol Cancer 9: 212, 2010.

23. Wanger RT, Xu X, Yi F, Merrill BJ and Coony AJ: Canonical Wnt $/ \beta$-catenin regulation of liver receptor homolog-1 mediates pluripotency gene expression. Stem cells 28: 1794-1804, 2010.

24. Conacci-Sorrell M, Simcha I, Ben-Yedidia T, Blechman J, Savagner P and Ben-Ze'ev A: Autoregulation of E-cadherin expression by cadherin-cadherin interactions: the roles of betacatenin signaling, Slug, and MAPK. J Cell Biol 163: 847-857, 2003.

25. Choi YS, Shim YM, Kim SH, Son DS, Lee HS, Kim GY, Han J and Kim J: Prognostic significance of E-cadherin and $\beta$-catenin in resected stage I non-small cell lung cancer. Eur J Cardiothorac Surg 24: 441-449, 2003.

26. Resnick MB, Routhier J, Konkin T, Sabo E and Pricolo VE: Epidermal growth factor receptor, c-MET, beta-catenin, and p53 expression as prognostic indicators in stage II colon cancer: a tissue microarray study. Clin Cancer Res 10: 3069-3075, 2004.

27. Zhang W, Chen $X$, Kato $Y$, Evans $M$, Yuan S, Yang $S$, Rychahou PG, Yang VW, He X, Evers BM and Liu C: Novel cross talk of Krüppel-like factor 4 and $\beta$-catenin regulates normal intestinal homeostasis and tumor repression. Mol Cell Biol 26: 2055-2064, 2006.

28. Evans PM, Chen X, Zhang W and Liu C: KLF4 interacts with $\beta$-catenin/TCF4 and blocks $\mathrm{p} 300 / \mathrm{CBP}$ recruitment by $\beta$-catenin. Mol Cell Biol 30: 372-381, 2010.

29. Zhu S, Tai C, MacVicar BA, Jia W and Cynader MS: Glutamatergic stimulation triggers rapid Krüpple-like factor 4 expression in neurons and the overexpression of KLF4 sensitizes neurons to NMDA-induced caspase-3 activity. Brain Res 1250: 49-62, 2009.

30. Li Y, Basang Z, Ding H, Lu Z, Ning T, Wei H, Cai H and Ke Y: Latexin expression is downregulated human gastric carcinomas and exhibits tumor suppressor potential. BMC Cancer 11: 121, 2011.

31. Shaheen FS, Znojek P, Fisher A, Webster M, Plummer R, Gaughan L, Smith GC, Leung HY, Curtin NJ and Robson CN: Targeting the DNA double strand break repair machinery in prostate cancer. PLoS One 6: e20311, 2011.

32. Ganesan K, Ivanova T, Wu Y, Rajasegaran V, Wu J, Lee MH, Yu K, Rha SY, Chung HC, Ylstra B, t Meije G, Lian KO, Grabsch H and Tan P: Inhibition of gastric cancer invasion and metastasis by PLA2G2A, a novel $\beta$-catenin/TCF target gene. Cancer Res 68: 4277-4286, 2008.

33. Yori JL, Johnson E, Zhou G and Keri RA: Krüppel-like factor 4 (KLF4) inhibits epithelial-to-mesenchymal transition through regulation of E-cadherin gene expression. J Biol Chem 285: 16854-16863, 2010.

34. Zhao X, Yang L and Hu J: Down-regulation of miR-27a might inhibit proliferation and drug resistance of gastric cancer cells. J Exp Clin Cancer Res 30: 55, 2011.

35. Bieker JJ: Krüppel-like factors: three fingers in many pies. J Biol Chem 276: 34355-34358, 2001.

36. Shie JL, Chen ZY, O'Brien MJ, Pestell RG, Lee ME and Tseng CC: Role of gut-enriched Krüppel-like factor in colonic cell growth and differentiation. Am J Physiol Gastrointest Liver Physiol 279: G806-G814, 2000

37. Rowland BD and Peeper DS: KLF4, p21 and context-dependent opposing forces in cancer. Nat Rev Cancer 6: 11-23, 2006.

38. Yoon HS and Yang VW: Requirement of Krüppel-like factor 4 in preventing entry into mitosis following DNA damage. J Biol Chem 279: 5035-5041, 2004.

39. Hu W, Hofstetter WL, Li H, Zhou Y, He Y, Pataer A, Wang L, Xie K, Swisher SG and Fang B: Putative tumor-suppressor function of Krüppel-like factor 4 in primary lung carcinoma. Clin Cancer Res 15: 5688-5695, 2009.

40. Yang Y, Goldstein BG, Chao HH and Katz JP: KLF4 and KLF5 regulate proliferation, apoptosis and invasion in esophageal cancer cells. Cancer Biol Ther 4: 1216-1221, 2005. 
41. Ton-That H, Kaestner KH, Shields JM, Mahatankoon CS and Yang VW: Expression of the gut-enriched Kruppel-like factor gene during development and intestinal tumorigenesis. FEBS Lett 419: 239-243, 1997.

42. Schulz WA and Hatina J: Epigenetic of prostate cancer: beyond DNA methylation. J Cell Mol Med 10: 100-125, 2006.

43. Katz JP, Perreault N, Goldstein BG, Lee CS, Labosky PA, Yang VW and Kaestner KH: The zinc-finger transcription factor Klf4 is required for terminal differentiation of goblet cells in the colon. Development 129: 2619-2628, 2002.

44. Dang DT, Bachman KE, Mahatan CS, Dang LH, Giardiello FM and Yang VW: Decreased expression of the gut-enriched Krüppel-like factor gene in intestinal adenomas of multiple intestinal neoplasia mice and in colonic adenomas of familial adenomatous polyposis patients. FEBS Lett 476: 203-207, 2000.

45. Katz JP, Perreault N, Goldstein BG, Actman L, McNally SR, Silberg DG, Furth EE and Kaestner KH: Loss of Klf4 in mice causes altered proliferation and differentiation and precancerous changes in the adult stomach. Gastroenterology 128: 935-945, 2005.

46. Stone CD, Chen ZY and Tseng CC: Gut-enriched Krüppel-like factors regulates colonic cell growth through APC/beta-catenin pathway. FEBS Lett 530: 147-152, 2002.

47. Logan CY and Nusse R: The Wnt signaling pathway in development and disease: Annu Rev Cell Dev Biol 20: 781-810, 2004.
48. Hervieu V, Lepinasse F, Gouyse G, Guillaud O, Barel C, Chanmbonniere ML, Bringuier PP, Poncet G, Lombard-Bobas C, Chawialle JA and Scoazec JY: Expression of $\beta$-catenin in gastroenteropancreatic endocrine tumours: a study of 229 cases. J Clin Pathol 59: 1300-1304, 2006.

49. Lin SY, Xia W, Wang JC, Kwong KY and Spohn B: Beta-catenin, a novel prognostic marker for breast cancer: its roles in cyclin D1 expression and cancer progression. Proc Natl Acad Sci USA 97: 4262-4266, 2000.

50. BianchiI F, Hu J, Pelosi G, Cirincione R, Ferquson M, Ratcliffe C, Di Fiore PP, Gatter K and Pastorino U: Lung cancers detected by screening with spiral computed tomography have a malignant phenotype when analyzed by cDNA microarray. Clin Cancer Res 10: 6023-6028, 2004.

51. Wong SC, Lo ES, Lee KC, Chan JK and Hsiao WL: Prognostic and diagnostic significance of $\beta$-catenin nuclear immunostaining in colorectal cancer. Clin Cancer Res 10: 1401-1408, 2004.

52. Czyzewska J, Guzińska-Ustymowicz K, Ustymowicz M, Pryczynicz A and Kemona A: The expression of E-cadherincatenin complex in patients with advanced gastric cancer: role in formation of metastasis. Folia Histochem Cytobiol 48: 37-45, 2010.

53. Sampieri CL, de la Peña S, Ochoa-Lara M, Zenteno-Cuevas R and León-Córdoba K: Expression of matrix metalloproteinases 2 and 9 in human gastric cancer and superficial gastritis. World $\mathbf{J}$ Gastroenterol 16: 1500-1505, 2010 